\title{
A FORMAÇÃO PROFISSIONAL INTEGRADA NO IFPR - CAMPUS CASCAVEL-PR: QUE FORMAÇÃO?'
}

Daniela Skrowonski ${ }^{2}$

José Luiz Zanella ${ }^{3}$

\begin{abstract}
Resumo: Esse estudo investiga a formação profissional integrada ao ensino médio desenvolvida pelos Institutos Federais de Educação, Ciência e Tecnologia, com campo de pesquisa restrito ao IFPR - Campus Cascavel-PR. O objetivo consiste em analisar a proposta de educação profissional integrada ao ensino médio do referido Instituto, verificando se a mesma apresenta direcionamento para uma formação politécnica/tecnológica. A metodologia utilizada foi a pesquisa bibliográfica e documental, entrevistas semiestruturadas e questionário, sendo estes últimos aplicados no Campus Cascavel. Como sujeitos envolvidos nas entrevistas, destacam-se os servidores do campus, especificamente a gestão, a equipe pedagógica e os docentes, além de discentes formandos, que responderam um questionário. Com base no estudo realizado, constatamos que mesmo diante de alguns desafios, como a falta de formação continuada, de recursos financeiros e de infraestrutura física, a educação profissional integrada ao ensino médio do IFPR - Campus Cascavel representa um caminho inicial para a formação politécnica/tecnológica, indo além das exigências do mercado, comprometendo-se com a formação integral do sujeito.

Palavras-chave: Educação Profissional Integrada ao Ensino Médio, Formação politécnica/tecnológica, Institutos Federais.
\end{abstract}

\section{THE INTEGRATED PROFESSIONAL EDUCATION AT IFPR - CAMPUS CASCAVEL -PR: WHICH TRAINING?}

\begin{abstract}
This study investigates the professional education integrated to the Secondary School Level developed by the Federal Institutes of Education, Science and Technology, with its research's field restricted to IFPR - Campus Cascavel - PR. The purpose is to analyze the proposal of integrated professional education to the Secondary School Level of this Institute, verifying if it is directed towards a polytechnic/ technological formation. The used methodology was the bibliographical and documentary research, semi-structured interviews and a questionnaire, these last two being applied at Campus Cascavel. As the subjects involved in the interviews, stand out the campus employees, specifically the management, the pedagogical team and the teaching staff, besides graduating students, who answered a questionnaire. Based on the fulfilled study, we found out that even in the face of some challenges, such as the lack of continuous training, financial resources and physical infrastructure, the professional education integrated to the Secondary School Level of IFPR - Cascavel Campus represents an initial path to polytechnic/ technological education, going beyond the demands of the market, committing itself to the full education of the individual.
\end{abstract}

Keywords: Professional Education Integrated to Secondary School Level, Polytechnic/Technological Training, Federal Institutes.

\section{Introdução}

Os Institutos Federais de Educação, Ciência e Tecnologia são integrantes da Rede Federal de Educação Profissional, Científica e Tecnológica, instituída em 2008, que ocupa todo o território brasileiro. Atualmente, somam 643 campi distribuídos em todas as unidades da federação, mais de um milhão de matrículas e cerca de 80 mil servidores (CONIF, 2018). São instituições incubidas de ofertar cursos que abrangem os diversos níveis da educação profissional

\footnotetext{
${ }^{1}$ Esse artigo se origina a partir da pesquisa de mestrado intitulada: "Educação profissional integrada ao ensino médio: uma análise da proposta no IFPR - Campus Cascavel”, desenvolvida pelos autores.

${ }^{2}$ Mestre em Educação pela Universidade Estadual do Oeste do Paraná - UNIOESTE - Campus Francisco Beltrão. Pedagoga do Instituto Federal de Educação, Ciência e Tecnologia do Paraná, Campus Avançado Quedas do Iguaçu. E-mail: danielaskro@gmail.com

${ }^{3}$ Doutor em Educação pela Universidade Estadual de Campinas. Professor efetivo da Universidade Estadual do Oeste do Paraná - UNIOESTE - Campus Francisco Beltrão. E-mail: zanellazl@ hotmail.com
} 
e tecnológica, desde a básica à pós-graduação, incluindo a formação de professores. Dessa forma, ofertam, prioritariamente, cursos técnicos integrados ao ensino médio, cursos de qualificação profissional ou formação inicial e continuada (FIC), superiores de tecnologia, bacharelados, licenciaturas e pós-graduação lato e stricto sensu, além da oferta de cursos à distância.

Os Institutos Federais foram criados com vistas à formação e qualificação de trabalhadores que atendam as demandas dos arranjos produtivos de cada contexto geográfico e socioeconômico. Ao mesmo tempo, são os maiores representantes da educação básica técnica no Brasil.

Contudo, nos Institutos Federais, a proposta de formação dos cursos técnicos integrados parece ter uma tensão entre, de um lado, a formação para atender os interesses do mercado (empreendedorismo) e, de outro, a formação integrada (politécnica/tecnológica). Diante desta aparente contradição, indagamos: A proposta de educação profissional integrada ao ensino médio dos Institutos Federais tem direcionamento para uma formação politécnica/tecnológica? Quais são os limites e possibilidades desta proposta de educação profissional integrada ao ensino médio?

A partir da problemática, nosso objetivo consiste em analisar a proposta de educação profissional integrada ao ensino médio do Instituto Federal de Educação, Ciência e Tecnologia do Paraná - Campus Cascavel, verificando se a mesma apresenta direcionamento para uma formação politécnica/tecnológica. Vale ressaltar que a pesquisa foi delimitada à educação profissional integrada ao ensino médio no IFPR - Campus Cascavel junto aos dois cursos da respectiva modalidade: Técnico em Informática Integrado ao Ensino Médio e Técnico em Análises Químicas Integrado ao Ensino Médio.

Os dados analisados resultam de pesquisa bibliográfica, documental, entrevistas semiestruturadas e questionário. A pesquisa bibliográfica fundamenta-se em autores da proposta de formação politécnica/tecnológica e da formação integrada na especificidade da sociedade brasileira, embasando-se no método materialismo histórico dialético e utilizando-se de autores como Marx, Frigotto, Saviani, Ramos, Ciavatta, Pacheco dentre outros. A pesquisa documental tem por base os documentos institucionais: Plano de Desenvolvimento Institucional, no qual está inserido o Projeto Pedagógico Institucional (2014-2018) e os Projetos Pedagógicos dos cursos Técnico em Informática Integrado ao Ensino Médio e Técnico em Análises Químicas Integrado ao Ensino Médio do IFPR - Campus Cascavel. As entrevistas semiestruturadas foram realizadas com nove servidores ( 1 técnico-administrativo e 8 docentes) do IFPR - Campus Cascavel e a aplicação de questionário a trinta e dois discentes formandos dos dois cursos integrados citados. 
Para a análise dos dados e informações coletadas utilizamos a técnica de análise de conteúdo. Tal técnica é constituída pelas seguintes etapas: 1 - pré-análise; 2 - exploração do material; e 3 - tratamento dos resultados, a inferência e a interpretação (BARDIN, 2006). Assim, a partir da exploração dos dados coletados, da análise realizada e à luz dos fundamentos teóricometodológicos respondemos as questões que norteiam essa pesquisa.

\section{A política de formação profissional dos IFs: os fundamentos da formação integrada}

Historicamente, a educação profissional no Brasil teve como enfoque a formação voltada exclusivamente para atender as demandas do mercado de trabalho, formação de mão de obra. Assim, nessa modalidade de educação, especialmente na escola pública, predominou o dualismo educacional, caracterizado de acordo com a formação ofertada aos sujeitos - formação manual ou intelectual; formação geral/propedêutica ou formação específica/profissional -, assim como na dualidade estrutural de classe social que marca a sociedade brasileira - burguesia e proletariado.

Atualmente, no contexto da reestruturação do capitalismo, a formação profissional fundamenta-se na teoria do capital humano rejuvenescida na proposta do empreendedorismo ${ }^{4}$, pois há lugar apenas para aqueles que se integram na sociedade do conhecimento, para os mais "competentes", aqueles que desenvolvem qualidades técnicas e psicossociais que interessam ao mercado (FRIGOTTO, 2011). Resulta daí o dualismo educacional que separa a formação teórica (científica/filosófica) da formação prática (profissão).

Em oposição à formação profissional dualista do mercado, desde o século XIX, Marx (1976, 1999), a partir de uma análise histórico-científica do desenvolvimento contraditório do modo de produção capitalista, verificou que o próprio desenvolvimento tecnológico proporciona as condições objetivas para uma formação escolar dos trabalhadores que seja tecnológica/politécnica. Mas, em função da propriedade privada dos meios de produção e da divisão técnica do trabalho, mantém-se a formação prática polivalente para a maioria dos trabalhadores e, para uma pequena parcela, formação tecnológica. Daí Marx propor que "não há dúvida de que a conquista inevitável do poder político pela classe trabalhadora trará a adoção do ensino tecnológico, teórico e prático nas escolas dos trabalhadores” (MARX, 1999, p. 553).

Esta perspectiva de formação proposta por Marx foi desenvolvida por Saviani com a denominação de formação politécnica.

Politecnia diz respeito ao domínio dos fundamentos científicos das diferentes técnicas que caracterizam o processo de trabalho produtivo moderno. Está relacionada aos fundamentos das diferentes modalidades de trabalho e tem

\footnotetext{
${ }^{4}$ Perspectiva da teoria do capital humano ressignificada em nova terminologia: "sociedade do conhecimento, qualidade total, pedagogia das competências, empregabilidade e empreendedorismo" (ver FRIGOTTO, 2011).
} 
como base determinados princípios, determinados fundamentos, que devem ser garantidos pela formação politécnica. Por quê? Supõe-se que, dominando esses fundamentos, esses princípios, o trabalhador está em condições de desenvolver as diferentes modalidades de trabalho, com a compreensão do seu caráter, da sua essência. Não se trata de um trabalhador adestrado para executar com perfeição determinada tarefa e que se encaixe no mercado de trabalho para desenvolver aquele tipo de habilidade. Diferentemente, trata-se de propiciar-lhe um desenvolvimento multilateral, um desenvolvimento que abarca todos os ângulos da prática produtiva na medida em que ele domina aqueles princípios que estão na base da organização da produção moderna (SAVIANI, 2003, p. 160).

$\mathrm{Na}$ especificidade da sociedade brasileira, um grupo de pesquisadores (FRIGOTTO, CIAVATTA, RAMOS, dentre outros), formularam a proposta de formação Ensino Médio Integrado, tendo como eixo trabalho, ciência e cultura. A denominação "integrado" visa, por um lado, superar o dualismo educacional e, de outro superar a justaposição entre formação geral e formação profissional. Entendem os autores que o jovem trabalhador brasileiro necessita ingressar no mercado de trabalho, daí a necessidade de o Ensino Médio atender a esta demanda, mas mantendo o princípio da formação politécnica/tecnológica.

Foi com base na perspectiva da formação tecnológica/politécnica denominada na especificidade brasileira de Ensino Médio Integrado que fundamentou-se a proposta de educação profissional dos Institutos Federais. Tais instituições representam uma alternativa para a superação da dualidade educacional que marcou a educação profissional, direcionando sua atuação para uma educação emancipatória.

Em sua proposta de formação, os Institutos Federais buscam integrar formação propedêutica com profissional, assim como teoria e prática nas atividades de ensino, pesquisa e extensão que são desenvolvidas, sendo esta centrada na compreensão do mundo do trabalho e não na formação exclusiva para o mercado de trabalho. Assim, a proposta exige uma outra postura, no sentido de superação do modelo hegemônico disciplinar; "significa pensar um profissional da educação capaz de desenvolver um trabalho reflexivo e criativo e promover transposições didáticas contextualizadas que permitam a construção da autonomia dos educandos" (PACHECO, 2011, p. 19).

Desse modo, a política de formação profissional dos Institutos Federais em cursos técnicos de nível médio propõe-se como formação integrada. Esta proposta fundamenta-se na formação politécnica, também denominada de tecnológica. Segundo Ciavatta (2014, p. 191), essa formação politécnica pode ser entendida como possibilidade de "formação em todos os aspectos da vida humana - física, intelectual, estética, moral e para o trabalho, integrando a formação geral e a educação profissional", o que pressupõe a totalidade no processo formativo. 
Ainda, para Ciavatta (2014), a formação integrada vai além da integração entre ensino médio e educação profissional, resgatando a concepção de educação politécnica, de educação omnilateral e de escola unitária.

\begin{abstract}
Ela [formação integrada] busca recuperar, no atual contexto histórico e sob uma específica de correlação de forças entre as classes, a concepção de educação politécnica, de educação omnilateral e de escola unitária [...]. Assim, essa expressão também se relaciona com a luta pela superação do dualismo estrutural da sociedade e da educação brasileira, a divisão de classes sociais, a divisão entre formação para o trabalho manual ou para o trabalho intelectual, e em defesa da democracia e da escola pública. (CIAVATTA, 2014, p. 197-198)
\end{abstract}

Assim, temos o entendimento de que o passo inicial para uma formação politécnica perpassa pelo currículo integrado. Por isso, para Ramos (2008),

A proposta de currículo integrado na perspectiva da formação politécnica e omnilateral dos trabalhadores [...] defende que as aprendizagens escolares devem possibilitar à classe trabalhadora a compreensão da realidade para além de sua aparência e, assim, o desenvolvimento de condições para transformá-la em benefício das suas necessidades de classe (RAMOS, 2008, p. 115).

Nesse sentido, salientamos que a proposta de currículo integrado na perspectiva politécnica/tecnológica é o fundamento da política de formação profissional dos IFs. A seguir, buscamos verificar em que medida a referida proposta de formação se realiza na especificidade do IFPR-Cascavel-PR.

\title{
A concepção sobre a Educação Profissional Integrada ao Ensino Médio no IFPR - Campus
}

\section{Cascavel - PR}

A partir da criação dos Institutos Federais, e mais especificamente da proposta de educação profissional integrada ao ensino médio, é possível verificar nos discursos dos documentos e legislações que norteiam tais instituições que o viés buscado tem sido de uma formação integral, em que ocorra o desenvolvimento pleno de todas as capacidades do indivíduo. É o que se visualiza no Projeto Pedagógico Institucional (PPI) do IFPR:

O processo educativo objetiva proporcionar uma formação integral, que possibilite o acesso a conhecimentos científicos e tecnológicos e promova a reflexão crítica sobre o contexto social e o mundo do trabalho, desenvolvendo a autonomia intelectual do estudante para que este consiga, por si próprio, formarse ou buscar a formação necessária na construção de seu itinerário profissional. (IFPR, PPI, 2014-2018, p. 56)

Desse modo, o que verificamos é a possibilidade de emancipação dos estudantes, a fim do desenvolvimento da consciência crítica necessária para vivência social e atuação profissional. Além do documento institucional, PPI, os Projetos Pedagógicos dos cursos técnicos também 
estão alinhados com a perspectiva de formação para além do mercado de trabalho, em que o estudante tenha clareza do seu papel na sociedade, considerando a integralidade das dimensões técnica e humana (PPC INFORMÁTICA, IFPR, CASCAVEL, 2013).

Portanto, os documentos sinalizam a educação profissional como potencializadora no processo de transformação social, por meio da formação de estudantes capazes de conhecerem as determinações da organização do trabalho na sociedade capitalista pela mediação da cultura e da ciência. Para Pacheco (2011, p. 22) o que está posto para os Institutos Federais "é a formação de cidadãos como agentes políticos capazes de ultrapassar obstáculos, pensar e agir em favor de transformações políticas, econômicas e sociais imprescindíveis para a construção de um outro mundo possível".

Por outro lado, nos documentos analisados também identificamos alguns fragmentos que alimentam a lógica capitalista, como por exemplo a formação de cidadãos empreendedores e o atendimento às demandas locais. Assim, o discurso em determinados trechos dos documentos soa como contraditório, sendo indefinido quanto à proposição da formação final do estudante. Isso é visualizado desde a missão do IFPR:

Promover a educação profissional e tecnológica, pública, de qualidade, socialmente referenciada, por meio do ensino, pesquisa e extensão, visando à formação de cidadãos críticos, autônomos e empreendedores, comprometidos com a sustentabilidade (IFPR, PDI, 2014-2018, p. 27).

Assim, a proposta parece oscilar entre uma formação tecnológica/politécnica e integral e, ao mesmo tempo, atender as demandas específicas do mercado, ou seja, uma formação técnicoprofissional (empreendedorismo).

Para conhecer a formação desenvolvida no IFPR - Campus Cascavel, para além dos documentos, entrevistamos nove servidores - gestão do campus, equipe pedagógica e docentes, além da aplicação de questionário junto aos discentes formandos dos cursos técnicos integrados.

Com relação aos servidores, constatamos que todos entendem que o objetivo da educação profissional integrada ao ensino médio é integrar a formação geral com a formação profissional, evitando o dualismo educacional. No entanto, revelam essa proposta como desafiadora, uma vez que existem alguns limites, como o despreparo para realizar a integração, a dificuldade em integrar determinados conteúdos ou mesmo a dificuldade na falta de tempo para planejamento coletivo.

A proposta é superar esse dualismo, é fazer uma educação integradora, não é aquela formação para o vestibular, é a formação para a formação técnica, mas uma formação que englobe a formação omnilateral do sujeito, para a politecnia. Isso é o que está nos documentos. (SERVIDOR 4, 2018) 
Em relação aos discentes, verificamos que a escolha pela educação profissional integrada ao ensino médio é motivada por diferentes fatores, como: possibilidade de uma dupla formação, ou seja, o ensino médio e o curso técnico; oportunidade de ingresso no mercado de trabalho por meio do curso técnico; qualidade na educação ofertada pelo Instituto Federal; melhor preparo para o ensino superior e/ou o curso técnico representa a área de interesse do discente.

Desse modo, constatamos que a maior motivação dos estudantes na escolha deve-se ao fator qualidade na educação do Instituto Federal. Essa qualidade pode ser verificada a partir do diferencial proporcionado na formação do estudante, como: a relação teoria e prática e a relação entre unidade e totalidade; a integração entre ciência, tecnologia e cultura como dimensões indissociáveis da vida humana e o ensino, a pesquisa e a extensão desenvolvidos na instituição (IFPR, PPI, 2014-2018).

A relação teoria e prática se faz presente nos cursos, especialmente, por meio de atividades ou projetos de ensino, pesquisa e extensão ${ }^{5}$, assim como por meio do estágio profissional. Isso é percebido a partir de exemplos dos servidores e discentes:

Por exemplo, ensinar ele a fazer o gênero carta de apresentação que ele vai utilizar lá no dia a dia, no mercado de trabalho. (SERVIDOR 3, 2018)

A aplicação do nosso conhecimento teórico em exemplos práticos, por meio de análises de caso, leitura de trabalhos já realizados na área, aulas práticas e visitas técnicas (DISCENTE 4, 2018)

O trabalho, a ciência, a tecnologia e a cultura, por sua vez, contribuem para integrar uma totalidade na formação do sujeito, sendo base para a proposta do ensino integrado. Nessa perspectiva, não há como conceber nenhuma atividade profissional com apenas um destes eixos, pois de acordo com Gramsci toda atividade humana requer, sempre e necessariamente, algum recurso intelectual, alguma habilidade física bem como a disposição necessária para tal (ARAUJO, 2014)

Em relação aos eixos nos cursos técnicos do campus Cascavel, de acordo com os servidores, os mesmos se fazem presentes por meio da realização de eventos, projetos e atividades extracurriculares. Um servidor especifica como percebe a presença de cada um dos eixos nos cursos

[...] a questão do trabalho fica mais evidente nessa formação deles para o mercado de trabalho, mercado profissional. O eixo de ciência vai envolver todas as áreas, a tecnologia também vai ficar mais evidente com as áreas técnicas, e a parte da cultura, [...] justamente para dar uma formação um pouco mais

\footnotetext{
5 Os projetos de ensino, pesquisa e extensão são desenvolvidos nas diferentes áreas do conhecimento, sendo exemplos no campus Cascavel: projeto de teatro, projeto de música, projeto da horta, projeto de análise de água das fontes, projeto de robótica, projeto de xadrez, projeto de formação continuada para professores, etc.
} 
abrangente para que eles não fiquem aqueles profissionais lá que sabe fazer, mas não sabe ler o mundo da volta dele. (SERVIDOR 5, 2018)

Contudo, entendemos de que para além de conceitos e nomenclaturas, o que se almeja é a compreensão da totalidade em determinado conteúdo, componente curricular e conhecimento. Logo, é importante que o trabalho, a ciência, a tecnologia e a cultura permeiem todo o currículo, procurando realizar um trabalho de forma não isolada, centrado na questão da formação humana integral que possibilite um conhecimento mais amplo, para além da segmentação em disciplinas. Por isso, para Pacheco (2011, p. 10), um dos objetivos basilares dos Institutos Federais consiste em "derrubar as barreiras entre o ensino técnico e o científico, articulando trabalho, ciência e cultura na perspectiva da emancipação humana".

No que compete ao ensino, pesquisa e extensão desenvolvidos na instituição, cabe destacar sua importância para o currículo integrado, conforme expõe este servidor.

Então, hoje o instituto federal é uma das únicas ou a única instituição, que no nível médio consegue oferecer a pesquisa e extensão, e quando eu falo em pesquisa e extensão aí sim eu tenho o ensino integrado. (SERVIDOR 6, 2018)

Todavia, os servidores também apontam algumas dificuldades quanto ao desenvolvimento de atividades dessa natureza, como por exemplo: a falta de verbas para a pesquisa, evidenciado por três servidores; a carga horária insuficiente para conciliar o ensino e pesquisa, dito por dois servidores; a dificuldade de integrar o tripé ensino, pesquisa e extensão, indicado por um servidor; a falta de estrutura para pesquisa (salas, laboratórios mais avançados, equipamentos), sinalizado por dois servidores e número inferior de ações e/ou projetos de extensão, também destacado por dois servidores.

Entretanto, mesmo com tais dificuldades e considerando que se trata de uma instituição recente, com servidores em contato inicial com a proposta, o campus Cascavel tenta perseguir a melhor forma de trabalhar a educação profissional integrada, o que contribui significativamente para a construção de uma base sólida de formação, sendo um elemento a ser considerado na educação politécnica.

Assim, para Araujo e Frigotto (2015) a proposição da formação integrada consiste em:

Não apenas uma forma de oferta da educação profissional de nível médio, o ensino integrado é uma proposição pedagógica que se compromete com a utopia de uma formação inteira, que não se satisfaz com a socialização de fragmentos da cultura sistematizada e que compreende como direito de todos ao acesso a um processo formativo, inclusive escolar, que promova o desenvolvimento de suas amplas faculdades físicas e intelectuais. (ARAUJO, FRIGOTTO, 2015, p. 62) 
Então, verificamos que uma proposta de formação integrada vai além da apropriação de conteúdos educacionais isoladamente, que não se limita ao conhecimento para avaliações, testes e concursos, mas se concretiza a partir de uma formação integral do ser humano, com o domínio dos diferentes fundamentos da ciência, que propiciem a capacidade intelectual necessária para uma atuação na sociedade para além dos interesses do mercado. Essa concepção visa romper com o dualismo educacional que permeia a educação, tendo relação imediata com a formação politécnica.

A partir da formação ofertada no campus Cascavel, os nove servidores evidenciam a evolução dos estudantes ao longo do curso, o que contribui tanto para a formação profissional quanto para a formação geral. Ao mesmo tempo, dois servidores também pontuam que a maioria dos estudantes vêm estudar no Instituto Federal em busca de uma melhor formação, que possa, inclusive, auxiliá-los na aprovação para o vestibular.

Diante disso, refletimos o quanto a educação pública em outras redes ainda precisa melhorar para que o adolescente não precise se sujeitar à formação profissional de nível médio, se assim o desejar. Dessa forma, fica evidente o estabelecimento da dualidade educacional de novo tipo, entre redes de ensino, conforme expõem Rummert, Algebaile e Ventura (2013). Também, a presença de uma dualidade estrutural nessa modalidade de ensino, pois aqueles adolescentes com famílias em condições sociais e econômicas mais favoráveis seguem seus estudos em nível superior, ao passo que os filhos dos desprovidos de tais condições vão para o mercado de trabalho.

O que não se pode deixar de registrar é que no atual sistema capitalista vivenciado as instituições necessitam formar para o mercado de trabalho. Todavia, precisam ir além, no sentido da formação de uma mão de obra qualificada, crítica e reflexiva, que pensa e entende a dimensão do trabalho que exerce, em que este não seja uma mera execução de tarefas que causem sua alienação social. Isso é elucidado por Ciavatta (2012), quando enfatiza que as instituições não devem reduzir a educação às necessidades do mercado de trabalho e ao mesmo tempo não devem ignorar as exigências da produção econômica, que é o campo onde os sujeitos sociais retiram os meios de vida.

Portanto, a educação profissional integrada ao ensino médio do IFPR - Campus Cascavel caminha na direção de uma formação politécnica/tecnológica, mas sem deixar de lado a preparação para o mercado de trabalho. Tendo em vista a sociedade atual, neoliberal, entendemos que esse direcionamento é necessário, pois caso contrário corre-se o risco da fragilização da instituição e/ou a desconsideração pelos sujeitos, já que faz-se necessário acompanhar o tempo presente. Assim, isso aparece como uma contradição na formação proposta pelos Institutos Federais. 


\section{A organização pedagógica e curricular da Educação Profissional Integrada ao Ensino} Médio do IFPR-Cascavel-PR

A organização curricular dos cursos do IFPR está alinhada com as Diretrizes Curriculares Nacionais para a Educação Profissional Técnica de Nível Médio (Parecer CNE/CEB n. 11/2012 e Resolução CNE/CEB n. 06/2012), quando prevê:

O IFPR, na organização dos seus cursos adota como pressupostos: a integração entre trabalho, ciência, tecnologia e cultura; a pesquisa como eixo orientador da prática pedagógica; a indissociabilidade entre teoria e prática e a interdisciplinaridade, visando à superação da fragmentação entre as áreas do conhecimento. (IFPR, PPI, 2014-2018, p. 56)

Ademais, a organização curricular no IFPR se desenvolve a partir dos seguintes princípios: "transversalidade; verticalização; flexibilidade; integração e interdisciplinaridade" (IFPR, PPI, 2014-2018, p. 58). Portanto, tais pressupostos e princípios preconizam uma formação humana integral, a partir da contribuição das diferentes áreas do conhecimento, a fim de que o indivíduo possa ter conhecimento do todo.

Araujo e Frigotto (2015, p. 69) apontam alguns princípios como orientadores para a organização de um currículo integrado: “a contextualização, a interdisciplinaridade e o compromisso com a transformação social". Entendemos, então, que o currículo integrado não pode prescindir da unidade entre os diferentes componentes curriculares, promovendo a relação e a contextualização entre os conteúdos abordados, a fim da formação de um sujeito com domínio dos conhecimentos científicos e tecnológicos para atuação social.

Como possibilidades pedagógicas para a interdisciplinaridade os projetos de ensino, pesquisa e extensão são apontados por cinco servidores. Além disso, os discentes também manifestam que os projetos desenvolvidos no turno oposto representam um diferencial na sua formação, o que contribui para um conhecimento integrado entre as diferentes áreas, assim como mais prático. Dos trinta e dois participantes, dezenove avaliam a experiência de forma positiva; seis afirmam ser incentivado, mas que nem todos têm acesso; três responderam que não participaram e outros três não responderam a pergunta.

A partir da participação dos estudantes nos projetos ocorre a iniciação científica, que possibilita a experimentação em várias áreas do conhecimento, constituindo uma proposta enriquecedora no currículo da instituição. Logo, destacamos que isso somente é possível quando existem condições para sua efetivação, perpassando por políticas alinhadas nessa perspectiva, por questões financeiras, de infraestrutura e de pessoal. 
Além dos projetos, no turno oposto às aulas ainda ocorre o atendimento aos estudantes. Sendo assim, os professores dispõem de horário para atividades de apoio ao ensino, que compreendem também horários de atendimento aos estudantes. Esses atendimentos funcionam como suporte no processo de aprendizagem, pois caso o estudante sinta alguma dificuldade, pode buscar auxílio individual junto ao professor da disciplina.

A fim de um trabalho mais eficaz, o campus Cascavel ainda dispõe de uma equipe multidisciplinar, que assessora o estudante em relação a diferentes questões envolvendo os estudos ou mesmo de ordem pessoal. Essa equipe é composta por diversos profissionais, como: três pedagogos, um assistente social, um psicólogo, dois técnicos em assuntos educacionais, três assistentes de alunos, um assistente em administração, um intérprete em libras e a chefia da seção pedagógica.

Nesse sentido, compreendemos que essa organização compõe mais um diferencial nos cursos técnicos do campus Cascavel. A possibilidade de suporte com diferentes profissionais, o atendimento junto ao professor de forma individualizada e a oportunidade de participar de projetos contribuem para a educação de qualidade. Dessa forma, o estudante tem condições de um desenvolvimento mais satisfatório, pois existem os recursos necessários. Segundo um dos discentes: “[...] aprendemos de fato a estudar e dar valor ao que aprendemos" (DISCENTE 22, 2018).

Isso também é sinalizado pelos demais discentes quando questionados se percebem diferenciais na formação em relação a amigos ou conhecidos que não cursam a educação profissional integrada ao ensino médio. As respostas concentram-se na qualidade da educação do Instituto Federal, na possibilidade de também ter a formação técnica junto ao ensino médio, no maior conhecimento proporcionado pelo Instituto Federal, no incentivo à pesquisa e extensão, na possibilidade de ingressar no mercado de trabalho a partir da formação, na diferença de abordagem dos conteúdos, nos professores qualificados, nos recursos ofertados pelo Instituto Federal (atendimentos, materiais, assistência estudantil ${ }^{6}$ ) e na aprendizagem de hábitos de estudo. Dentre os trinta e dois que responderam, apenas um estudante menciona não perceber diferenciais.

Ainda no que diz respeito à organização curricular, identificamos que as matrizes curriculares dos cursos técnicos integrados atendem as orientações da Resolução CNE/CEB n. 06/2012, indicando os componentes curriculares de cada etapa, bem como trazem os

\footnotetext{
${ }^{6}$ A assistência estudantil tem garantido o acesso, permanência e êxito dos estudantes no IFPR. Tal programa é direcionado àqueles que se encontram em situação de vulnerabilidade socioeconômica. São ofertados, por meio da Política de Assistência Estudantil do IFPR, programas que contemplam as seguintes áreas: alimentação, moradia, transporte, esporte, projetos acadêmicos, monitoria, eventos, NAPNE - Núcleo de Atendimento às Pessoas com Necessidades Educacionais Específicas.
} 
conhecimentos nas áreas de linguagens e códigos, ciências humanas, matemática e ciências da natureza, além dos relativos à formação profissional. Contudo, reconhecemos que são mais estudadas as áreas clássicas como a Matemática e a Língua Portuguesa, presentes em todos os anos dos cursos, em detrimento de outras como Artes, Educação Física, História, Geografia, Filosofia e Sociologia, em que é inferior a carga horária.

Quanto a este aspecto, de modo geral os estudantes avaliam como satisfatória a formação, tanto a nível geral quanto profissional, representando um total de vinte e seis respostas positivas. Outros seis discentes concentram suas respostas na diferenciação entre ambas as formações, seja pela forma de abordagem dos professores em aula, seja pela insuficiência de aulas práticas na área técnica ou ainda pela divergência de carga horária em determinados componentes curriculares.

Assim, depreendemos que pelo fato dos Institutos Federais ofertarem educação profissional, alguns componentes curriculares do ensino médio são prejudicados em relação à carga horária, o que pode em algum momento comprometer a aprendizagem de determinado conteúdo.

Ressaltamos que isso perpassa pela questão da organização do trabalho pedagógico, incluindo o planejamento docente. Quanto a este aspecto, a Resolução no 002/2009 do IFPR dispõe que a carga horária para esta atividade é de quatro horas semanais, sendo considerada insuficiente para quatro dos servidores entrevistados, pois o tempo de planejamento é o mesmo independentemente do número de aulas do docente. É o que se verifica por meio da fala de um servidor: "[...] na carga horária nossa nós temos 4 horas que eu considero muito pouco para preparar material, corrigir todas as atividades, planejar aula independente da quantidade de aulas que você tem" (SERVIDOR 7, 2018).

No que tange à questão da formação continuada, dos servidores entrevistados, sete apontam que apenas no início do ano ocorre a semana pedagógica, com espaços para discussão sobre alguma temática específica. É o que especifica um servidor: "Geralmente a formação pedagógica ela ocorre só mesmo, no nível de instituição, na semana pedagógica, que seria uma semana no começo do ano, onde se reúne esse colegiado e se discute" (SERVIDOR 6, 2018).

Entretanto, durante as entrevistas foi possível constatar que o IFPR - Campus Cascavel vem apresentando uma iniciativa na perspectiva de formação continuada, por meio de um projeto de extensão, envolvendo as diferentes redes (federal, estadual e municipal) e os estudantes, especialmente do campus, dos cursos de licenciatura e especialização. Quanto à reitoria do IFPR, a partir das entrevistas, também identificamos algumas iniciativas, de forma on-line, sem a exigência de participação, o que ocorre por meio do tempo disponível e interesse de cada servidor. 
Além disso, em relação à formação continuada precisamos considerar a formação pedagógica, uma vez que muitos dos docentes que ingressam nos Institutos Federais não são licenciados ou não apresentam formação pedagógica, apresentando apenas a experiência de empresas ou de acordo com sua titulação, de pesquisas realizadas em universidades. Também precisamos considerar que parte considerável dos docentes não possuem formação na perspectiva da educação profissional integrada ao ensino médio, devido ao fato de nunca terem trabalhado com a educação profissional ou que muitas vezes, são profissionais recém-formados que passam em concurso e ingressam nos Institutos Federais.

Sobre essa questão da formação pedagógica, a Resolução CNE/CEB n. 06/2012 evidencia que aos docentes graduados, não licenciados, é assegurado o direito de participar ou ter reconhecidos seus saberes profissionais em processos destinados à formação pedagógica ou à certificação da experiência docente.

Ainda considerando a questão de formação pedagógica, é possível identificar que alguns aspectos precisam ser tratados no campus Cascavel, conforme sinalizado por quatro discentes:

De modo geral, há uma boa execução da formação técnica, mas há algumas divergências quanto à formação básica, devido ao fato de que muitos professores possuem uma boa formação em suas respectivas áreas, mas não a respeito do ensino (DISCENTE 4, 2018).

Isso também é advertido por dois servidores:

Então esse é um desafio urgente para a instituição: criar uma política de formação continuada, num primeiro momento para as pessoas que não tem essa formação pedagógica, que é um problema sério, que eles têm uma formação muito técnica, tem um viés tecnicista da educação e existe essa dificuldade de discutir o que é educação integrada, o que é educação tecnológica. É um desafio enorme. Então, hoje essa discussão não só no campus Cascavel, mas na instituição como um todo, precisa se discutir uma política para isso. (SERVIDOR 9, 2018)

Sendo assim, reconhecemos que ainda é algo que necessita de investimento, o que perpassa por uma questão institucional, ou seja, o IFPR necessita ampliar a política de formação continuada, inclusive, a fim de atender o que menciona o PPI quanto a formação dos professores com o perfil da instituição. Além disso, vem ao encontro do perfil profissional desejado pela Rede Federal, pois a proposta dos Institutos Federais requer um docente capacitado para trabalhar com a formação integrada, assim como de forma verticalizada, devido à atuação em diferentes níveis de ensino.

Sendo assim, reconhecemos que a formação continuada é uma questão urgente nos Institutos Federais, também sinalizada no campus Cascavel. Mesmo com as oportunidades para qualificação, como especializações, mestrados e doutorados, verificamos a necessidade de um 
enfoque maior na educação profissional politécnica/tecnológica, perpassando pela formação pedagógica, pois nem sempre o que é buscado por estes profissionais apresenta esse direcionamento, tendo em vista a necessidade de também qualificarem-se na sua área de formação.

Portanto, a proposta de formação integrada é desafiadora, pois requer uma postura ativa, de busca, de encontro com os demais docentes, a fim de sua efetividade. Então, o desenvolvimento de iniciativas de formação continuada na perspectiva da formação integrada com viés politécnico/tecnológico precisa ser tarefa urgente de cada campus, Instituto Federal e Rede Federal.

\section{Considerações Finais}

Ao analisarmos a educação profissional integrada ao ensino médio dos Institutos Federais, particularmente do IFPR - Campus Cascavel, identificamos que tais instituições têm demonstrado todo seu potencial enquanto política pública de formação profissional. Um conjunto de fatores contribui para isso: um projeto que contempla uma legislação afinada com os propósitos educacionais, ou seja, diretrizes curriculares nacionais que norteiam o trabalho pedagógico; assim como uma política de formação e qualificação do corpo docente e técnico administrativo, com respectivas remunerações condignas e planos de carreira; além do regime de dedicação exclusiva dos docentes; da política de assistência estudantil; das atividades de ensino, pesquisa e extensão oportunizadas; da infraestrutura adequada e as boas condições de trabalho.

Assim, essa análise permite compreender que a instituição alvo desta pesquisa, o IFPR Campus Cascavel, tem buscado o direcionamento para a formação politécnica/tecnológica. É uma proposta que não nega as exigências do mercado, mas vai além, pois tanto nos documentos analisados quanto a partir das respostas dos sujeitos participantes, ou seja, servidores e discentes, é possível identificar o compromisso com uma formação integral, que considera os princípios científicos das diferentes técnicas, tendo suporte nos eixos trabalho, ciência, tecnologia e cultura.

Da mesma forma, na busca pela formação integral ou no direcionamento para a formação politécnica/tecnológica, identificamos alguns desafios que dificultam a efetiva formação no campus Cascavel, como:

- a dificuldade de integração de determinados conteúdos/conhecimentos, que perpassa pela falta de planejamento coletivo e pela falta de compreensão do que é currículo integrado/formação integrada por parte de alguns profissionais;

- a falta de formação continuada em dois sentidos: pedagógica aos docentes, compreendendo a superação do modelo convencional de ensino; e, de concepção de 
ensino profissional, para todos os servidores, incluindo a compreensão dos fundamentos pedagógicos de constituição da Rede Federal;

- a carga horária insuficiente para desenvolver ensino, pesquisa e extensão;

- a falta de infraestrutura física para atender as demandas do campus;

- a escassez de recursos financeiros para o aprimoramento das ações de ensino, pesquisa e extensão;

- a dificuldade de identificação da proposta de formação integral, já que há contradições na formação ofertada que estão de acordo com exigências legais;

- a insuficiência de carga horária em alguns componentes curriculares relativos ao Ensino Médio, comprometendo a abordagem de determinados conteúdos.

Portanto, mesmo com tais dificuldades cabe evidenciar que é preciso, nas brechas da sociedade capitalista, tentar fazer uma educação mais humana, integral, que tenha como viés a politecnia. O IFPR - Campus Cascavel ainda é uma instituição muito recente, que requer tempo para consolidar-se no município e região, além de tempo para compreender esse viés politécnico buscado, sinalizado em seus documentos.

A integração, que é um dos elementos da formação politécnica/tecnológica, ainda está sendo construída pelo campus Cascavel. Aos poucos, os profissionais estão aprendendo a fazer a integração. No entanto, cabe a ressalva de que a proposta pedagógica da instituição precisa ser compreendida por todos os profissionais, a fim de que haja o entendimento de que esse é o caminho. Não basta fazer a integração de componentes curriculares se não houver uma práxis da proposta com compreensão de seus sujeitos.

Sendo assim, torna-se importante o processo de construção coletiva dos documentos institucionais, a fim de possibilitar o conhecimento da proposta de formação da instituição. Logo, o Plano de Desenvolvimento Institucional e o Projeto Pedagógico Institucional tornam-se documentos essenciais para elaboração dos Projetos Pedagógicos dos cursos, sendo que devem refletir no plano de trabalho docente e por sua vez, na prática pedagógica.

Entendemos, dessa forma, que a formação politécnica perpassa pela compreensão e prática docente, representando ainda um caminho inicial o ensino médio integrado. Mas, é preciso ir além da integração entre formação geral e formação profissional, contemplando também a integração entre as diferentes áreas do conhecimento.

Da mesma forma, além de docentes engajados com esse viés formativo, faz-se necessário que os discentes também tenham uma atitude interessada, no sentido do desejo de aprender, de pesquisar e de colaborarem para o processo de construção do conhecimento. Também, é importante que existam condições dentro das instituições, como infraestrutura e recursos 
adequados, formação continuada aos profissionais e carga horária compatível para o atendimento de todas as atividades com qualidade.

Considerando esses aspectos, compreendemos que os Institutos Federais se configuram como um espaço diferenciado de formação e emancipação humana, representando um caminho inicial para a formação politécnica/tecnológica. Assim, um projeto nesse formato não pode ser interrompido, pois além de atender às novas configurações do mundo do trabalho, também tem contribuído para a elevação da escolaridade dos trabalhadores de forma crítica e reflexiva. Por isso, ratificamos que cabe valorizar e lutar por essa conquista, a fim de que tenha continuidade e seja ainda mais aprimorada.

\section{Referências}

ARAUJO, Ronaldo Marcos de Lima. Práticas pedagógicas e ensino integrado [recurso eletrônico]. 1. ed. Curitiba: Instituto Federal do Paraná, 2014. (Coleção formação pedagógica; v. 7).

ARAUJO, Ronaldo Marcos de Lima; FRIGOTTO, Gaudêncio. Práticas Pedagógicas e ensino integrado. In: Revista Educação em Questão (UFRN. Impresso), v. 52, n. 38, p. 61-80, maio/ago 2015.

BARDIN, Laurence. Análise de conteúdo. (L. de A. Rego \& A. Pinheiro, Trads.). Lisboa: Edições 70, 2006.

BRASIL. Parecer CNE/CEB N. 11/2012. Diretrizes Curriculares Nacionais para a Educação Profissional Técnica de Nível Médio. Diário Oficial da União, Brasília, 04 de setembro de 2012, Seção 1, p. 98.

BRASIL. Resolução CNE/CEB N. 06/2012. Define Diretrizes Curriculares Nacionais para a Educação Profissional Técnica de Nível Médio. Diário Oficial da União, Brasília, 04 de setembro de 2012.

CIAVATTA, Maria. A formação integrada: a escola e o trabalho como lugares de memória e de identidade. In: FRIGOTTO, Gaudêncio; CIAVATTA, Maria; RAMOS, Marise Nogueira (Orgs.). Ensino médio integrado: concepção e contradições. São Paulo: Cortez, 2012.

CIAVATTA, Maria. O ensino integrado, a politecnia e a educação omnilateral. Por que lutamos? In: Revista Trabalho \& Educação. Belo Horizonte, v. 23, n. 1, jan.-abr., 2014, p. 187-205.

CONIF. Conselho Nacional das Instituições da Rede Federal de Educação Profissional, Científica e Tecnológica. 2018. Disponível em: http://portal.conif.org.br/br/. Acesso em: 04 fev. 2018.

FRIGOTTO, Gaudêncio; CIAVATTA, Maria; RAMOS, Marise Nogueira (Orgs.). Ensino médio integrado: concepção e contradições. São Paulo: Cortez, 2005.

FRIGOTTO, Gaudêncio. Novos fetiches mercantis da pseudo teoria do capital humano no contexto do capitalismo tardio. In: ANDRADE, Juarez de e PAIVA, Lauriana G. de (orgs) As políticas públicas para a educação no Brasil contemporâneo. Juiz de Fora: Editora UFJF, 2011, p.18-35.

INSTITUTO FEDERAL DO PARANÁ. Plano de Desenvolvimento Institucional - PDI (20142018). Versão revisada, março de 2017. Disponível em: http://info.ifpr.edu.br/wp- 
content/uploads/PDI-2014-2018-Vers\%C3\%A3o-Revista-2017-2018-Final-30032017.pdf.

Acesso em: 03 mar. 2018.

INSTITUTO FEDERAL DO PARANÁ. Resolução $n^{\circ}$ 002/2009 - Conselho Superior. Estabelece Diretrizes para a Gestão das atividades de ensino, pesquisa e extensão no âmbito do Instituto Federal do Paraná - IFPR. Disponível em: http://paranagua.ifpr.edu.br/wpcontent/uploads/2011/11/resolucao-002-2009AtividadesDocentes.pdf. Acesso em: 23 jun. 2018.

INSTITUTO FEDERAL DO PARANÁ. Projeto Pedagógico do curso Técnico em Informática na forma de oferta integrada ao ensino médio. Campus Cascavel. 2013. Disponível em: http://cascavel.ifpr.edu.br/wp-content/uploads/2014/12/PPC-T\%C3\%A9cnico-emInform\%C3\%A1tica-INTEGRADO.pdf. Acesso em: 21 mai. 2018.

INSTITUTO FEDERAL DO PARANÁ. Projeto Pedagógico do curso Técnico em Análises Químicas na forma de oferta integrada ao ensino médio. Campus Cascavel. 2015. Disponível em: http://cascavel.ifpr.edu.br/wp-content/uploads/2015/09/PPC-Atualizado1.pdf. Acesso em: 28 mai. 2018.

MARX \& ENGELS. Textos sobre educação e ensino. São Paulo: Editora Moraes, 1976.

MARX, Karl. O Capital: crítica da economia política. 17. ed. Rio de Janeiro: Civilização Brasileira, 1999. Livro 1.

PACHECO, Eliezer Moreira. Institutos Federais: uma revolução na educação profissional e tecnológica. In: PACHECO, Eliezer Moreira (Org.). Institutos Federais: uma revolução na educação profissional e tecnológica. Brasília/São Paulo: Fundação Santillana: Moderna, 2011.

RAMOS, Marise Nogueira. Currículo Integrado. In: PEREIRA, Isabel Brasil; LIMA, Júlio César França. (Orgs.). Dicionário da Educação Profissional em Saúde. 2. ed. rev. ampl. - Rio de Janeiro: EPSJV, 2008.

RUMMERT, Sonia Maria; ALGEBAILE, Eveline; VENTURA, Jaqueline. Educação da classe trabalhadora brasileira: expressão do desenvolvimento desigual e combinado. In: Revista Brasileira de Educação, v. 18, p. 717-738, 2013.

SAVIANI, Dermeval. O choque teórico da politecnia. In: Revista Trabalho, Educação e Saúde, 1 (1), 2003, p. 131-152.

\section{Recebido em 05/08/2019. Aprovado em 15/11/2019.}

